\title{
Retraction Note to: Research on coastline climate characteristics and urban media art based on GIS image recognition
}

\author{
Wenhua Huang ${ }^{1}$. Jinglong Jiang ${ }^{2}$
}

Published online: 11 November 2021

(c) Saudi Society for Geosciences 2021

Retraction Note to: Arabian Journal of Geosciences (2021) 14: 1382 https://doi.org/10.1007/s12517-021-07623-0

The Editor-in-Chief and the Publisher have retracted this article because the content of this article is nonsensical. The peer review process was not carried out in accordance with the Publisher's peer review policy. The authors have not responded to correspondence regarding this retraction.

The original article can be found online at https://doi.org/10.1007/ s12517-021-07623-0.

Wenhua Huang

hwh66339@sina.com

1 School of Civil Engineering and Architecture, Shaanxi University of Technology, Hanzhong 723001, Shaanxi, China

2 School of Biological Science and Engineering, Shaanxi University of Technology, Hanzhong 723001, Shaanxi, China 